\title{
Left Suprarenal Vein
}

National Cancer Institute

\section{Source}

National Cancer Institute. Left Suprarenal Vein. NCI Thesaurus. Code C53138.

A vein that drains blood from the left adrenal gland into the left renal artery. 